\title{
A IMAGEM DO NEGRO NO FUTEBOL BRASILEIRO: RETRATOS DO PERÍODO ENTRE COPAS (1938-1958)
}

\author{
LA IMAGEN DEL NEGRO EN EL FÚTBOL BRASILEÑO: RETRATOS DEL PERÍODO \\ ENTRE COPAS (1938-1958)
}

\section{THE IMAGE OF THE BLACK IN THE BRAZILIAN FOOTBALL: PORTRAITS OF THE PERIOD BETWEEN WORLD CUPS (1938-1958)}

\author{
Vinícius AZEVEDO ${ }^{1}$
}

RESUMO: O presente artigo pretende abordar, ainda que de maneira breve, a construção da imagem do negro no futebol brasileiro sob o contexto das Copas do Mundo do período de 1938 a 1958. Destaca-se o papel dos cronistas esportivos de jornais como Diário de Pernambuco e Folha da Tarde, bem como o papel do Estado Novo na construção de um novo ideário político de identidade nacional.

PALAVRAS-CHAVE: Copa do Mundo. Futebol brasileiro. Questão racial.

RESUMEN: El presente artículo pretende abordar, aunque de manera breve, la construcción de la imagen del negro en el fútbol brasileño bajo el contexto de las Copas del Mundo del período de 1938 a 1958. Se destaca el papel de los cronistas deportivos de periódicos como Diario de Pernambuco y Diario de Pernambuco, Folha da Tarde, así como el papel del Estado Nuevo en la construcción de un nuevo ideario político de identidad nacional.

PALABRAS CLAVE: Copa del Mundo. Fútbol brasileño. Cuestión racial.

ABSTRACT: The present paper intends to portray, although briefly, the construction of the image of the black in the Brazilian soccer under the context of World Cups from the period of 1938 to 1958. It is important to highlight the role of sports journals such as Diário de Pernambuco and Folha da Tarde, as well as the role of the Estado Novo in the construction of a new political ideology of national identity.

KEYWORDS: World Cup. Brazilian soccer. Racial issue.

${ }^{1}$ Universidade Estadual Paulista (UNESP), Araraquara - SP - Brasil. Graduando em Ciências Sociais. ORCID: https://orcid.org/0000-0001-6540-1946. E-mail: viniazv@gmail.com 


\section{Introdução}

Tratar sobre questões raciais no Brasil é uma decisão que carece de bastante cuidado com os pormenores. Abordar a temática em relação ao futebol significa aludir, quase que obrigatoriamente, ao mito da democracia racial presente em Gilberto Freyre. Analisar o contexto envolto na participação da seleção brasileira em Copas do Mundo realizadas entre 1938 a 1958 incute em discorrer, ainda que de maneira breve, as mudanças sociais e políticas ocorridas no Brasil em apenas duas décadas. Tais mudanças, atadas também ao quadro internacional, perpassam por períodos determinantes para nossa historiografia: a Segunda Guerra Mundial e o pós-guerra, o fenômeno populista e o nacional-desenvolvimentismo brasileiro e, em especial, a leitura racial presente em todos esses momentos.

O esperançoso clima político, econômico e cultural, que se seguiu à Segunda Guerra Mundial, caracterizou, segundo Hobsbawm (2004), os anos 1950 em boa parte do mundo, os quais, por isso mesmo, puderam ser retrospectivamente sintetizados sob o rótulo de "Anos Dourados" (DIAS, 2011). Dias² (2011) analisa que "no Brasil, esse período apresentou um caráter inteiramente diverso tanto daquele que o antecedeu, a Era Vargas, quanto daquele que o seguiu, o regime militar, em termos de normalidade democrática, e guarda uma relevância intrínseca, pelo interregno que representou de confiança e otimismo generalizado quanto ao futuro do país por parte dos seus cidadãos."

Não raro, os Anos Dourados brasileiros simbolizaram a execução de projetos intrépidos, como o desenvolvimento da indústria automobilística e a construção da nova capital - Brasília, no centro-oeste do país -, como parte do plano de governo de Juscelino Kubitschek. Nesse período também é elaborada e promulgada a primeira lei contra a discriminação racial no Brasil, de autoria do deputado Afonso Arinos de Melo Franco em $1951^{3}$. Em termos culturais, foi também nesse período que despontou a Bossa Nova na música popular brasileira. Reavendo o orgulho nacional golpeado e ferido em 1950, o Brasil conquista pela primeira vez, em 1958, a Copa do Mundo.

\section{8: Gilberto Freyre e o foot-ball mulato}

2 Ver DIAS, Aline Passeri et al. Sobre a memória social dos “Anos Dourados": Fusca, Copa do Mundo, Bossa Nova e Missa Brasil. Psicologia: Teoria e Prática, v. 13, n. 3, p. 110-123, 2011.

${ }^{3}$ Para uma análise desse processo, ver GRIN, Monica e MAIO, Marcos Chor. O antirracismo da ordem no pensamento de Afonso Arinos de Melo Franco. Topoi, v. 14, n. 26, jan./jul., p. 33-45, 2013. 
A Copa do Mundo de 1938, realizada na França entre 4 e 19 de junho, inaugura não somente a primeira vez em que o Brasil sobe ao pódio em mundiais - alcançando o terceiro lugar, atrás de Itália e Hungria, respectivamente - mas também marca, tendo em base as boas atuações da escrete ${ }^{4}$ brasileira, a incorporação do futebol à teoria racial de Gilberto Freyre. O time, composto notadamente por negros e mestiços de origem pobre, é tomado como base de apoio para a defesa da brasilidade futebolística, ou o assim chamado por Freyre foot-ball mulato. Dias após a vitória brasileira em Bordeaux no dia 12 de junho contra a Tchecoslováquia, que garantiu o avanço às semifinais, Freyre publica no Diário de Pernambuco:

Acaba de se definir de maneira inconfundível um estilo brasileiro de futebol, e esse estilo é uma expressão a mais do nosso mulatismo ágil em assimilar, dominar, amolecer em dança, curvas ou em músicas, as técnicas européias ou norte-americanas mais angulosas para o nosso gosto: sejam elas de jogo ou de arquitetura. Porque é um mulatismo o nosso - psicologicamente, ser brasileiro é ser mulato - inimigo do formalismo apolíneo sendo dionisíaco a seu jeito o grande feito mulato (FREYRE, 1938).

Recorrendo de um discurso romantizado, Freyre busca destacar virtudes decorrente de vínculos assentados entre raças diferentes, as quais se tornavam mais inflamadas no ato do futebol. A construção de sua análise aponta para que, frente ao rigor físico dos europeus, o negro brasileiro havia adotado a sinuosidade dos corpos. Isto, no que lhe diz respeito, não era inerente ao futebol. A ligeireza dos brasileiros teria sua gênese ligada, nem mais nem menos, a expressões populares folclóricas e musicais; tais como meneios originários do carnaval, os passes oblíquos do samba e a capacidade de esquiva da capoeira. Assim, o futebol entraria no salão de expressões de brasilidade como elemento que carrega em si outros componentes já arraigados na cultura brasileira, como afirma ainda no mesmo artigo publicado pelo Diário de Pernambuco:

O nosso estilo de jogar futebol me parece contrastar com o dos europeus por um conjunto de qualidades de surpresa, de manha, de astúcia, de ligeireza e ao mesmo tempo de brilho e de espontaneidade individual em que se exprime o mesmo mulatismo de que Nilo Peçanha foi até hoje a melhor afirmação na arte política. Os nossos passes, os nossos pitus, os nossos despistamentos, os nossos floreios com a bola, tem alguma coisa de dança ou capoeiragem que marca o estilo brasileiro de jogar futebol, que arredonda e adoça o jogo inventado pelos ingleses e por outros europeus jogado tão angulosamente, tudo isso parece exprimir de modo interessantíssimo para psicólogos e os sociólogos o mulatismo flamboyant e ao mesmo tempo malandro que está hoje em tudo que é afirmação verdadeira do Brasil (FREYRE, 1938).

${ }^{4}$ Do inglês scratch, significa seleção de futebol, elenco de um time. 
Ou ainda mais tarde, em 1945 na obra Sociologia:

De maneira inconfundível formou-se um estilo brasileiro de futebol; e esse estilo é uma nova expressão da nossa mulatice, perito em assimilação, domínio e abrandamento coreógrafo sinuoso e musical das técnicas européias e norte-americanas, que são muito angulosas para o nosso gosto - trata-se de técnicas de jogo ou de arquitetura. Pois nosso tipo de mulatice [...] é inimigo do formalismo apolíneo, é o dionisíaco na sua mobilidade. [...] No futebol, como na política, a mulatice brasileira caracteriza-se pelo prazer da elasticidade, da surpresa, da retórica, que lembra passos de dança e fintas de capoeira (FREYRE, 1945. p. 421- 222).

Junior (2013) destaca que Freyre não dispõe de tais elementos, à primeira vista apostos, como categorias supressórias, já que, para o autor, a distinção da sociedade brasileira está na flexibilidade e na maleabilidade em diferentes situações, de maneira que se tornou possível "uma convivência harmoniosa". Tal argumento cooperou para a criação de um mito em que as polarizações foram modificadas por relações pacíficas, levando a uma visão idílica da realidade (COSTA, 1998). Dessa forma, o mito da democracia racial, por sua vez, foi uma distorção da realidade das relações raciais existentes no Brasil, passando de um modelo paternalista a um modelo competitivo à estagnação de um conflito social.

Como bem nos assegura Junior (2013), pode-se dizer que para Gilberto Freyre qualquer objeto que fosse importado, incluindo o futebol, seria adaptado no Brasil pela nossa cultura híbrida. Neste contexto, fica claro que valor da cultura brasileira, para esse autor, está na relação estabelecida com os antagonismos sociais, tais como senhor e escravo, brancos e pretos. É possível constatar, contudo, que sob a ótica de Freyre, a partir dessa convivência tensa, porém harmoniosa, que se criou a riqueza da nossa cultura. Não é exagero afirmar que, em toda essa série, a figura do mulato pode sintetizar e expressar esse processo.

\section{O ideário político do Estado Novo e identidade nacional}

A modificação do bloco de poder em 1937 contribuiu para a redefinição da identidade nacional, aliada a vicissitudes no campo cultural e social no país. Assim, emergem intelectuais para compor esse extenso campo ideológico no centro dessa sociedade civil com desejo de edificar-se. Acompanhado de um processo de modernização econômico-social que se deu de modo "prussiano" - ou seja, com a conservação de traços pré-capitalistas (COUTINHO, 1990), seja na infraestrutura ou no Estado -, as mudanças culturais desse período conservam traços de uma relação de dependência política e econômica em relação aos padrões europeus. É nesse sentido que alguns autores como José Murilo de Carvalho e Carlos Nelson Coutinho recorrerem 
à categoria de nacional-popular, cunhado pelo cientista político marxista Antonio Gramsci, para explicar a construção do ideário político do Estado Novo.

Em Gramsci, a cultura exerce o papel fundamental de mediação entre os processos históricos de transformação da sociedade e a construção de uma nova hegemonia de classe na sociedade civil (ALENCAR, 2017). Na prática, se faz necessário forjar condições políticas e culturais em que o partido político e os intelectuais engendrem e assimilem esses princípios básicos nas novas relações sociais, que também apreende novas relações econômicas e políticas, bem como novas condutas éticas e morais. O futebol, interpretado como síntese de múltiplas determinações da sociedade brasileira, torna-se campo político para a transformação cultural pretendida pelo ideário do Estado Novo, que encontra nesse horizonte a "consciência atuante da necessidade histórica, como protagonista de um drama histórico real e efetivo" (GRAMSCI, 1978, p. 9) da superação do impasse racial e da mestiçagem.

Nessa direção, José Murilo de Carvalho aponta que a principal inovação envolvida nesse processo foi o esforço para criar uma visão positiva do povo brasileiro - contestada por grande parte da intelectualidade até a década de 1930 -, já que "o Brasil era o povo brasileiro, às elites cabia tirar desse povo e de sua cultura a inspiração de brasilidade" (CARVALHO, 1999, p. 360). Dentre os intelectuais responsáveis por essa guinada de pensamento sobre o povo brasileiro, Gilberto Freyre, em Casa Grande \& Senzala (1933), aparece como um pensador oriundo da elite política que tinha uma visão positiva sobre mestiçagem, contribuindo, entre outras coisas, para a adoção oficial de um posicionamento de governo que enaltecia o popular em detrimento do erudito ou, em outras palavras, o povo sobre a elite.

A retomada da visão positiva do povo e suas adversidades fizeram com que a mistura de raças e a integração dos negros brasileiros não mais fossem tratadas como entrave para o progresso do desenvolvimento nacional, sendo transformado em certa medida, numa etapa ou caminho para a ascensão social. Porém, é possível avistar que a liberdade e a participação não levam automaticamente à resolução dos problemas sociais e que, tendo como cenário os anos 1930 sob o governo de Getúlio Vargas, a sensação de conquista da cidadania por meio dos direitos civis e pela exaltação da origem étnica das classes subalternas foram usadas como moeda de troca dos direitos políticos suprimidos pelo Estado Novo. De acordo com Carvalho (2001), no Brasil primeiro vieram os direitos sociais, implantados em períodos de supressão dos direitos políticos e de redução dos direitos civis por um ditador que se tornou popular. Dessa forma, não é exagero afirmar que é possível haver direitos civis sem direitos políticos (CARVALHO, 2001, p. 219). 


\section{O prelúdio: 1950 e 1954}

Após hiato entre o Mundial de 1938 e a Segunda Guerra Mundial, a realização da Copa do Mundo retorna à atividade. O país escolhido para sediar os jogos de 1950 é o Brasil. Tal escolha tem como cenário político e social o Brasil governado por Getúlio Vargas, e como afirma Roberto Da Matta (apud MORAES NETO, 2000): “o início de uma década na qual o Brasil buscava marcar o seu lugar como nação que tinha um grande destino a cumprir" na direção da consolidação da brasilidade e da difusão da imagem para fora de um país que caminhava em direção ao desenvolvimento (COSTA et al., 2015).

Colocava-se como necessário atender a demanda internacional do pós-guerra em que a metodologias científicas baseadas em diagnósticos e banco de dados se coloca como exigência da Organização das Nações Unidas (ONU) e seus agentes financeiros como o Banco Mundial e o Fundo Monetário Internacional (FMI). Ocorre também nesse período, em 1948, a criação da Cepal (Comissão Econômica para a América Latina e o Caribe), estratégia para o desenvolvimento dos países da América Latina.

Calcado no sentido de subdesenvolvimento e de dependência, o Brasil começa a edificar, no final da década de 1950, a participação em um sistema de "espetáculo" e de capital altamente especializado, do qual ocorre, ainda que de forma progressiva, a conversão da dependência por intermédio da subordinação formal em dependência mediante subordinação real, ou seja, o futebol brasileiro, bem como seus jogadores acaba por se tornarem ativos econômicos a serem exportados como matéria-prima para o mercado mundial (MARINI, 2013, p. 48). Além disso, o futebol nacional passa a configura-se como produtor de matéria-prima para a Europa, em detrimento de uma autonomia do futebol brasileiro, ou mesmo, de uma posição central nesse mercado. Nesse movimento, o futebol brasileiro se subordina não apenas ao capital comercial, mas também e, sobretudo, ao capital industrial e financeiro internacionais (COUTINHO, 1990, p. 40). Essa transfiguração cria, segundo Carlos Nelson Coutinho, novas disposições para a história cultural brasileira.

Sob esse quadro internacional, organizar a primeira Copa do Mundo no pós-guerra, construir o maior estádio do mundo - o Maracanã - e propiciar um crescente desenvolvimento de sua indústria e ainda conquistar o título inédito era condicionante para inserir o Brasil ao tão sonhado patamar de país de "primeiro mundo" e se afirmar nacionalmente. Em campo, derrota para o Uruguai no dia 16 de julho de 1950 no quadrangular final ${ }^{5}$ em pleno Maracanã com

5 Na verdade, a partida entre Brasil e Uruguai não era a final (no sentido que atribuímos hoje). Acorre que pela primeira e última vez o mundial teve uma mudança de formato que possibilitou esse errôneo - porém aceitável - 
recorde de público em Copas do Mundo $^{6}$. Dessa forma, dolorosamente, o último objetivo falhou. A culpa pela derrota foi imputada em especial ao goleiro Barbosa, ao zagueiro Juvenal e ao lateral-esquerdo Bigode, todos negros.

Apoiado no tentame de 1950, que vai da exaltação à decepção, o futebol brasileiro buscou se estabilizar-se novamente para a Copa de 1954. Parte da reconstrução se deu pela tentativa de uma preparação profissional e planejada da seleção. No entanto, para além das ações racionais e concretas, o caráter simbólico das mudanças e da reestruturação almejada destacou-se na escolha de mudar o uniforme da seleção, trocando as camisas brancas de 1950 pelas amarelas ou pela instauração em 1954 do ritual de beijar a Bandeira Nacional antes da entrada da equipe em campo (COSTA et al., 2015 apud NOGUEIRA et al., 1994).

Quatro anos mais tarde, a organização do mundial volta a ter como sede um país europeu. Dessa vez, em ocasião do $50^{\circ}$ aniversário de fundação da FIFA (Federação Internacional de Futebol), a Copa do Mundo de 1954 foi realizada na Suíça, país-sede da organização. Durante a fase de grupos, a goleada contra o México e um empate de um gol para cada lado contra a Iugoslávia garante o avanço às quartas de final para seleção brasileira. A equipe adversária da próxima etapa seria a atual medalhista de ouro dos jogos olímpicos realizados dois anos antes: a poderosa ${ }^{7}$ Hungria. Mesmo jogando sem o principal e mais perigoso jogador húngaro ${ }^{8}-$ Ferenc Puskás - , jornais brasileiros da época assinalavam essa partida como sendo "O jogo do século" 9 .

A queda diante da Hungria não provocou o mesmo trauma de quatro anos antes. Dessa vez, a imprensa brasileira leu o jogo de maneira em que por mais que a seleção brasileira tenha sido superior, a vitória húngara fora garantida sob inferioridade técnica, como retrata a capa da Folha da Manhã de 29 de junho de 1954: “[...] os húngaros foram inferiores em todos os pontos de vista. Admitimos o valor do futebol magiar, mas a técnica brasileira é insuperável"10.

entendimento histórico. Para saber mais: GILARDI, Juan José Torres. 1950: o olhar da imprensa. Revista Contemporânea, n. 10 p. 128-129, 2008.

${ }^{6}$ Até hoje, nenhuma outra partida em Copas do Mundo superou o público de 173.850 pagantes. The Maracanazo marvels in numbers. Disponível em: https://www.fifa.com/worldcup/news/the-maracanazo-marvels-in-numbers2909382. Acesso em 20 de junho de 2018.

${ }^{7}$ BRÁS, O. Os super-homens. Folha da Manhã, São Paulo, p. 7, 22 jun. 1954a. Acervo Folha. Disponível em: https://acervo.folha.com.br/index.do. Acesso em 20 de junho de 2018.

${ }^{8}$ CHIORINO, Aroldo. Com Puskas ou sem Puskas passaremos pelo Brasil. Folha da Manhã, São Paulo, p. 7, 25 jun. 1954b.

${ }_{9}^{9}$ MENDES, A. O jogo do século não tem vencedor antecipado. Folha da Manhã, São Paulo, p. 7, 26 jun. 1954. Acervo Folha. Disponível em: https://acervo.folha.com.br/index.do. Acesso em 20 de junho de 2018.

${ }^{10}$ ELIMINADA a seleção brasileira em um jogo no qual deixou patente a sua superioridade. Folha da Manhã, São Paulo, capa, 29 jun. 1954. Acervo Folha. Disponível em: https://acervo.folha.com.br/index.do. Acesso em 20 de junho de 2018. 
Entretanto, de acordo com Costa et al (2015) em referência a Von der Lippe e MacLean (2008), os jogadores brasileiros foram retratados pelos jornais ingleses, noruegueses e suíços como "tecnicamente brilhantes" e "indisciplinados", mas ao mesmo tempo "primitivos" e de "sangue-quente". Os estereótipos raciais foram utilizados como forma de desvendar o comportamento dos brasileiros em relação aos húngaros e tinham como pano de fundo a classificação entre culturas em que os brasileiros se encontravam inferiorizados em comparação aos europeus,

Os brasileiros não eram apresentados como sem autocontrole apenas por sua negritude, mas também por suas origens sul-americanas. Como 'negros', os brasileiros eram menos civilizados do que os húngaros, como latinos eles eram mais voláteis, como seus homólogos do sul da Europa (COSTA et al., 2015 apud VON DER LIPPE; MACLEAN, 2008, p. 84).

Ainda de acordo com Costa et al. (2015) "as derrotas nacionais por um bom tempo foram explicadas por uma leitura de tipo psicológica do caráter nacional”. É nesse sentido que Nelson Rodrigues (1993) afirma que era necessário controle e a vontade para obter sucesso, características as quais faltava ao brasileiro em momentos de decisão. Além disso, o autor refere-se o insucesso contra o Uruguai, em 1950, e Hungria, em 1954, sob o escopo extensivo de caráter nacional:

E não era uma pane individual: era um afogamento coletivo. Naufragaram, ali, os jogadores, os torcedores, o chefe da delegação, a delegação, o técnico, o massagista. Nessas ocasiões, falta o principal. Estão a postos os jogadores, o técnico e o massagista. Mas quem ganha e perde as partidas é a alma. Foi a nossa alma que ruiu face à Hungria, foi a nossa alma que ruiu face ao Uruguai. [...] só um Freud explicaria a derrota do Brasil frente à Hungria, do Brasil frente ao Uruguai e, em suma, qualquer derrota do homem brasileiro no futebol ou fora dele (COSTA et al., 2015 apud RODRIGUES, 1993, p. 26).

\section{8: Plano Paulo Machado de Carvalho}

Passados vinte anos desde a derrota brasileira para a Itália em Marselha no dia 16 de junho de 1938, a seleção brasileira vai à Suécia para a disputa de mais uma Copa do Mundo para enfim sagrar-se campeã. Com o acúmulo de experiências e análise de fatores que influíram negativamente a imagem do Brasil e dos jogadores brasileiros nas duas últimas edições do mundial - em 1950 e 1954 -, uma equipe de jornalistas e dirigentes esportivos, selecionados pela Confederação Brasileira de Desportos (CBD), recebeu a tarefa de criar um Projeto 
Modernizador para o escrete nacional, que representaria o Brasil de Pelé - então com 17 anos sem a coroa de Rei do futebol - na Copa do Mundo de 1958.

Esse projeto, que ficou conhecido como Plano Paulo Machado de Carvalho tinha como objetivo, segundo Junior (2013) afirmar que "em última instância, (...) as elites locais estavam envergonhadas por serem representadas pelos negros/mulatos, incultos, desdentados e com grandes dificuldades de autocontrole em situações de adversidade", tal projeto, buscava "educálos, por meio de um planejamento de cunho pedagógico, que buscou modificar a aparência física, os hábitos culturais e o comportamento dos jogadores brasileiros".

Tendo como momento histórico a transição do modelo populista característico do governo de Getúlio Vargas aos moldes nacional-desenvolvimentista de Juscelino Kubitschek, o selecionado nacional atuaria "de maneira que eles [os jogadores] conseguissem representar a imagem de um país moderno, que havia superado o atraso sociocultural - normalmente atribuído a mitos como a mistura de raças e a falta de autocontrole do homem brasileiro".

A preparação montada pela CBD se estruturava para exemplificar que assim como o modelo econômico brasileiro, a seleção brasileira apresentaria jogadores livres de suas determinações naturais - tais como a inferioridade racial latino-americana assinalada por jornalistas europeus em 1954. Desse modo, Junior (2013) em referência a Rodrigues (2007), analisa que o relatório apresentado por João Havelange - presidente da CBD à época - consistia em "quem não se ajustasse ao programa que fizemos com a ajuda de médicos e psicólogos seria cortado da seleção. Só iria para a Copa da Suécia quem estivesse mentalmente preparado".

Mario Filho $^{11}$, jornalista com fortes influências freyreanas, descreveu estes acontecimentos da seguinte forma, passado a conquista da Copa de 1958:

[...] A CBD queria levar o menor número de pretos para a Suécia. Não esquecera 56, o relatório de Flávio Costa aconselhando, por causa do preto Sabará, a convocação só de jogador que, pelo menos, soubesse vestir-se e sentar-se a uma mesa. Daí a preocupação de um escrete, senão branco, o menos preto possível. Ainda se discutia a deterioração do mulato, mais do mulato do que do preto, em clima nórdico. Portanto a preocupação da CBD não era racista: ela acreditava mais no branco para jogar no frio, embora a época do campeonato do mundo caísse no verão sueco. A prova do nãoracismo está na convocação dos mulatos e pretos que acabaram jogando e contribuindo, decisivamente, para a vitória brasileira. [...] A preocupação em embranquecer o escrete chegou a tal ponto que na estréia contra a Áustria o único preto foi Didi. Era uma posição, a de Didi, em que não havia escolha. O reserva era outro preto: Moacir. Onde se podia escolher entre um branco e um

${ }^{11}$ Sobre as influências do cronista Mario Filho na construção da imagem do negro no futebol brasileiro, ver: HAAG, Fernanda Ribeiro. Mario Filho e o negro no futebol brasileiro: uma análise histórica sobre a produção do livro. Esporte e Sociedade, ano 9, n 23, mar. 2014. 
preto ficava-se inicialmente com o branco (RODRIGUES FILHO, 1964. p. 322-323).

Enquanto dentro do campo o preparo físico começa a pautar as decisões da comissão técnica, fora dele as mensagens manifestadas pelos cronistas esportivos expõem a forma de exibir a aspiração de que o futebol fosse o meio de emancipação dos negros e mestiços. Os literatos buscavam associar o sucesso do futebol a uma das formas do negro ser admitido e, como resultado, “embranquecer".

\section{Uma consideração longe do final}

A reconstrução histórica da imagem do negro atrelado à formação do ideário do futebol brasileiro é um processo contraditório que tange a inserção da sociedade brasileira na modernidade. Alguns cronistas, envoltos pelas teorias raciais de sua época, por vezes, constroem uma imagem teatralizada da apreensão nacional em superar o atraso; em superar o racismo como evidência de progresso.

Destarte, o futebol se coloca como alternativa de compreensão do "caráter nacional brasileiro", em que o trauma de 1950 foi narrado como a evidência de um povo incauto. Depois da drástica partida diante do Uruguai, a seleção brasileira voltou a ter um goleiro negro em copas apenas em 2006 (Dida), 56 anos após daquele que talvez tenha sido o pior dia de Barbosa - o goleiro daquele 16 de julho. Já em 1954, se chegou a presumir que devido ao seu povo miscigenado o Brasil era por essência um país afugentado.

O retrato pintado pelos cronistas esportivos, influenciados por Gilberto Freyre, mostrava o futebol flamboyant como fruto do apanhado cultural entre as diferentes raças. O coro feito por parte da elite dirigente do Brasil mostrava uma preocupação em relação à forma em que o país seria representado. Tal preocupação era fundada no fato de que parte significante do selecionado brasileiro era composto por negros, mestiços e/ou de origem pobre - condição que fazia com que o padrão ideal não correspondesse com os vários tipos de problemas apresentados por esses jogadores, como o baixo nível cultural e a estética nada adequada ao padrão europeu.

Em 1958, ápice da crença desenvolvimentista, da construção de Brasília e da aceleração da industrialização, o escrete nacional foi à Suécia sob descrédito por parte dos torcedores brasileiros. Talvez, por ironia do futebol, a seleção conquistou em territórios europeus a primeira Copa do Mundo. O triunfo sustentou a edificação de um novo imaginário coletivo 
nacional, que tem no governo de Juscelino Kubitscheck o arauto de uma marca bem-sucedida de modernidade.

A conquista do campeonato associado a transformações na infraestrutura econômica brasileira ao final da década de 1950 não separou, ainda que após inúmeras tentativas, a constituição ideal que separam, no corpo da sociedade, "o que é" do que "deveria ser" (FERNANDES, 2009) ou então, o Brasil real - o do racismo incrustado no seio da sociedade do Brasil ideal - teorizado por Freyre e sua democracia racial.

Mesmo passados oitenta anos do foot-ball mulato de Leônidas da Silva e sessenta da primeira conquista brasileira com Pelé, Garrinha e companhia, posteriores inúmeros esforços de intelectuais, atletas e cronistas esportivos em sanar a problemática da discriminação racial no esporte comumente associado à brasilidade, o racismo infelizmente ainda se mostra presente na sociedade e na prática esportiva em geral. Não se esgotam, ainda em memória, lamentáveis casos de injúrias raciais acorridos recentemente. Seja o goleiro Aranha (Santos) em partida pela Copa do Brasil contra o Grêmio em Porto Alegre, Elias (Corinthians) contra o Danúbio (Uruguai) pela Libertadores e Neymar e Daniel Alves atuando pelo Barcelona em partidas pelo Campeonato Espanhol são apenas breves exemplos de narrativas de cunho racista passado por jogadores brasileiros em diversos cenários e contextos regionais.

O impasse da questão racial mostra-se como registro para que se possa constatar a existência do racismo na sociedade brasileira, o que coloca em debate o mito da democracia racial. Assim, para Emília Viotti da Costa (1988), a compreensão das relações raciais no Brasil, da formação do mito e a crítica passa pelo entendimento do sistema de clientelismo e patronagem, assim como o seu desarranjo, ainda que enfraquecidos, tais padrões de relação ainda não estão completamente enterrados no seio da sociedade brasileira.

\section{REFERÊNCIAS}

ALENCAR, Mônica Maria Torres de. Gramsci e a perspectiva nacional-popular no âmbito da Cultura. O Social em Questão, ano XX, n. 39, set./dez., p. 185-210, 2017.

CARVALHO, José Murilo de. Brasil: nações imaginadas. In: Pontos e bordados: escritos de história e político. Belo Horizonte: Editora UFMG, 1999.

CARVALHO, José Murilo de. Cidadania no Brasil: o longo caminho. Rio de Janeiro: Civilização Brasileira, 2001.

COSTA, Emilia Viotti. O Mito da Democracia Racial. In: Da monarquia à república: momentos decisivos. São Paulo: Editora Unesp, 1988. 
COSTA, Felipe Rodrigues et al. Batalha de Berna (1954): a luta pelos sentidos de identidade no campo de futebol. Movimento, UFRGS, v. 21, 2015.

COUTINHO, Carlos Nelson. Cultura e Sociedade no Brasil: ensaios sobre ideias e formas. Belo Horizonte: Oficina de Livros, 1990.

FERNANDES, Florestan. Nós e o marxismo. São Paulo: Expressão Popular, 2009.

FREYRE, Gilberto. Foot-ball mulato. Diário de Pernambuco. Recife, 17 jun. 1938.

GRAMSCI, Antonio. Maquiavel, a Política e o Estado Moderno. 3 ed. Rio de Janeiro: Civilização Brasileira, 1978.

JUNIOR, Miguel Arcanjo de Freitas. Vitórias e derrotas de um futebol mestiço: algumas reflexões sobre a questão racial no Brasil. Emancipação. Ponta Grossa, v. 1, 2013.

MARINI, Ruy Mauro. Subdesenvolvimento e revolução. Florianópolis: Insular, 2013.

\section{Como referenciar este artigo}

AZEVEDO, Vinícius. A imagem do negro no futebol brasileiro: retratos do período entre Copas (1938-1958). Rev. Sem Aspas, Araraquara, v. 8, n. 1, p. 45-56, jan./jun. 2019. e-ISSN: 23584238. DOI: $10.29373 /$ sas.v8i1.12547.

Submetido em: 18/05/2019

Aprovado em: 30/06/2019 